\title{
High level of HIV-1 drug resistance among patients with HIV-1 and HIV-1/2 dual infections in Guinea-Bissau
}

\author{
Sanne Jespersen ${ }^{1,2^{*}}$, Martin Tolstrup ${ }^{2}$, Bo Langhoff Hønge ${ }^{1,2,3}$, Candida Medina ${ }^{4}$, David da Silva Té4, \\ Svend Ellermann-Eriksen ${ }^{5}$, Lars Østergaard ${ }^{2}$, Christian Wejse ${ }^{2,6}$, Alex Lund Laursen ${ }^{2}$ for The Bissau HIV cohort \\ study group
}

\begin{abstract}
Background: With the widespread use of antiretroviral treatment (ART) in Africa, the risk of drug resistance has increased. The aim of this study was to evaluate levels of HIV-1 resistance among patients with HIV-1 and HIV-1/2 dual infections, treated with ART, at a large HIV clinic in Guinea-Bissau.

Findings: Patients were selected from the Bissau HIV cohort. All patients had HIV-1 or HIV-1/2 dual infection, a CD4 cell count performed before and 3-12 months after starting ART, and a corresponding available plasma sample. We measured viral load in patients with HIV-1 $(n=63)$ and HIV-1/2 dual $(n=16)$ infections a median of 184 days after starting ART (IQR: 126-235 days). In patients with virological failure (defined as viral load $>1000$ copies/ml) and with sufficient plasma available, we performed an HIV-1 genotypic resistance test. Thirty-six patients (46\%) had virological failure. The CD4 cell count did not predict treatment failure. Of the 36 patients with virological failure, we performed a resistance test in 15 patients $(42 \%)$, and nine patients $(9 / 15 ; 60 \%)$ had resistance mutations. The most common mutation was $\mathrm{K} 103 \mathrm{~N}$, which confers high-level resistance to non-nucleoside reverse transcriptase inhibitors (NNRTI). No major mutations against protease inhibitors (PI) were found.

Conclusions: Our results showed that patients with HIV-1 and HIV-1/2 dual infections in Guinea-Bissau had a high rate of virological failure and rapid development of NNRTI resistance. It remains to be determined whether a more robust, PI-based treatment regimen might benefit this population more than NNRTIs.
\end{abstract}

Keywords: HIV-1, HIV-1/2 dual infection, Sub-Saharan Africa, Drug resistance, Antiretroviral treatment, Guinea-Bissau

\section{Findings}

Widespread use of antiretroviral treatment (ART) in Africa has increased the risk of drug resistance [1]. Factors that contribute to drug resistance include lack of plasma viral load monitoring [2], treatment interruptions due to drug stocking discontinuities [3], and drug interactions [4].

Most patients in Africa initiate ART with two nucleoside/ nucleotide reverse transcriptase inhibitors (NRTIs) and one non-nucleoside reverse transcriptase inhibitor (NNRTI) [5]. Africans have a high risk of developing the K103N NNRTI

\footnotetext{
* Correspondence: sanne.jespersen@clin.au.dk

${ }^{1}$ Bandim Health Project, Indepth Network, Apartado 861, Bissau,

Guinea-Bissau

${ }^{2}$ Department of Infectious Diseases, Aarhus University Hospital, Palle

Juul-Jensens Boulevard 99, 8200 Aarhus N, Denmark

Full list of author information is available at the end of the article
}

mutation, which is connected to poor adherence, due to a common genetic polymorphism that causes slow plasma NNRTI clearance and functional NNRTI monotherapy, when treatment is interrupted [6].

The West African country, Guinea-Bissau, has the highest HIV-2 prevalence worldwide [7-9]. HIV-2 is naturally resistant to NNRTIs [10], hence, patients with HIV-2 or HIV-1/2 dual infections must be treated with a protease inhibitor (PI)-based regimen. Differences in HIV-1 and HIV-2 resistance patterns may lead to complex drug resistance challenges for ART options in HIV-1/2 dual infections. This study is the first to report data on HIV resistance in Guinea-Bissau among patients with HIV-1 and HIV-1/2 dual infections. Based 
on data from neighboring countries, we suggest that HIV resistance may be a substantial problem [11-13].

\section{Methods}

This retrospective, follow-up study accessed data from a clinical HIV cohort at Hospital Nacional Simão Mendes, in Bissau, the capital of Guinea-Bissau [14].

Whenever a CD4 cell count is performed, surplus plasma is stored in a biorepository in Aarhus, Denmark. From this repository, we identified data for adult patients with HIV-1 or HIV-1/2 dual infections that had CD4 cell counts and stored plasma samples acquired before and after 3-12 months of ART. HIV-1/HIV-2 discrimination was performed with a SD Bioline HIV $1 / 2$ 3.0 test (Standard Diagnostics Inc, Kyonggi-do, South Korea). All stored plasma from patients with HIV-1/2 dual infections underwent an immunofluorescence discriminatory HIV-test (INNO-LIA; Innogenetics, Ghent, Belgium) [15]. When INNO-LIA and Bioline produced divergent results, INNO-LIA was considered the gold standard.

HIV-1 viral load was measured at the Department of Clinical Microbiology, Aarhus University Hospital, Denmark, with $\mathrm{COBAS}^{\circ}$ AmpliPrep/COBAS ${ }^{\odot}$ TaqMan $^{\circ}$ (Roche Diagnostics $\mathrm{GmbH}$, Mannheim, Germany). The lower limit of detection was $20 \mathrm{copies} / \mathrm{ml}$. Virological failure was defined as a viral load $>1000$ copies $/ \mathrm{ml}$ [5].

When sufficient plasma was available, we studied HIV-1 genotypic resistance in patients with virological failure by sequencing the protease and reverse transcriptase genes with ViroSeq ${ }^{\circ} 2.0$ (Abbott Laboratories, Illinois, USA). Mutations were classified as minor or major according to ART resistance consensus statements from the Stanford HIV RT and Protease Sequence database [16]. Subtype classifications were extracted from the Stanford database.

We used the Chi-square test for categorical variables to compare characteristics of patients with HIV-1 and HIV-1/2 dual infections, and patients with or without virological failure. We compared continuous variables with the Wilcoxon rank-sum test (non-normal distributions). The significance level was set at 0.05 . Statistical analyses were performed with Stata IC 11.0 (StataCorp, College Station, Texas, USA).

All patients provided voluntary, signed, dated, informed consent, or fingerprints when illiterate, prior to enrolment into the cohort. The ongoing HIV cohort studies were approved by the national ethics committee of Guinea-Bissau (Parecer NCP/No.15/2007).

\section{Results}

Viral load was measured in stored plasma samples from patients with HIV-1 $(\mathrm{n}=63)$ and HIV-1/2 dual $(\mathrm{n}=16)$ infections, acquired before and 3 to 12 months after (median 184 days, interquartile range (IQR): 126-235 days) starting ART (Table 1). No patient was pregnant
Table 1 Patient characteristics

\begin{tabular}{|c|c|}
\hline Characteristic & $\begin{array}{l}\text { Number of patients }(\%) \text {, unless } \\
\text { other indicated (total } \mathrm{N}=79 \text { ) }\end{array}$ \\
\hline \multicolumn{2}{|l|}{ Sex } \\
\hline Females & $47(59)$ \\
\hline Males & $32(41)$ \\
\hline Age at inclusion, median years (IQR) & $36(28-43)$ \\
\hline \multicolumn{2}{|l|}{ HIV-type } \\
\hline HIV-1 & $63(80)$ \\
\hline $\mathrm{HIV}-1 / 2$ & $16(20)$ \\
\hline $\begin{array}{l}\text { Baseline CD4 cell count, median } \\
\text { cells/ } / \mu \text { (IQR) }\end{array}$ & $134(62-207)$ \\
\hline $\begin{array}{l}\text { Baseline viral load, median copies/ml } \\
\text { (IQR) }\end{array}$ & $73,473(3,798-264,033)$ \\
\hline \multicolumn{2}{|l|}{ Baseline ART } \\
\hline 2 NRTIs + 1 NNRTI & $53(67)$ \\
\hline $2 \mathrm{NRTIS}+1 \mathrm{PI}$ & $23(29)$ \\
\hline 3 NRTIS & $3(4)$ \\
\hline $\begin{array}{l}\text { Post ART CD4 cell count, median } \\
\text { cells/HI (IQR) }\end{array}$ & $217(157-310)$ \\
\hline $\begin{array}{l}\text { Post ART viral load, median copies/ } \\
\text { ml (IQR) }\end{array}$ & $203(0-25.153)$ \\
\hline
\end{tabular}

IQR: Interquartile range.

and no information was available regarding ART during previous pregnancies.

Patients with HIV-1 and HIV-1/2 dual infections showed no significant differences in HIV-1 viral load (85,373 vs. 39,555 copies $/ \mathrm{ml}, \mathrm{p}=0.37$ ) or $\mathrm{CD} 4$ cell count (114 vs. 177 cells $/ \mu \mathrm{l}, \mathrm{p}=0.10)$. At $3-12$ months after starting ART, 36 patients (46\%) developed virological failure (Figure 1), but these patients were distributed similarly between HIV-1 and HIV-1/2 dual infection groups $(30 / 63=48 \%$ vs. $6 / 16=38 \%$, respectively; $p=0.47)$. The presence or absence of virological failure did not affect the proportion of patients ( $14 \%$ vs. $16 \%$, respectively; $\mathrm{p}=0.77$ ) that showed decreased CD4 cell counts after starting ART.

Of the 36 patients with virological failure, we performed successful resistance tests in 15 (42\%). Of these, eight (60\%) showed resistance to at least one antiretroviral drug: one $(7 \%)$ patient was resistant to NRTIs, four (27\%) to NNRTIs, and four (27\%) to both. No patient showed major PI resistance.

Twelve patients were taking NNRTIs; of these, seven (58\%) were resistant to NNRTIs. The most common NNRTI resistance mutation was K103N (5/12, 42\%), which caused high-level resistance against efavirenz and nevirapine. One male patient with NNRTI resistance had not received NNRTI treatment but PI treatment. Among the 15 patients tested for resistance (Table 2), the most common NRTI mutation was M184V (4/15 patients, $27 \%)$. Only one patient $(1 / 15,7 \%)$ had thymidine 


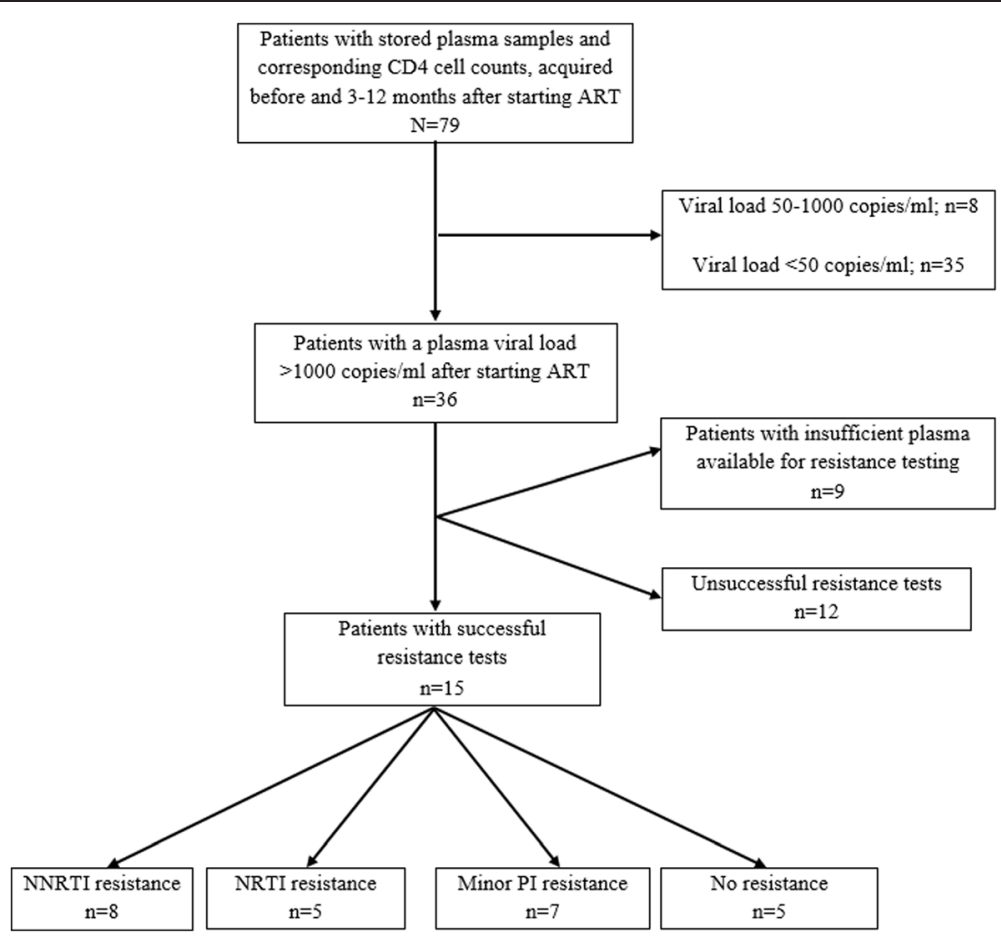

Figure 1 Flow chart of patient selection. ART: antiretroviral treatment; NNRTI: non-nucleoside reverse transcriptase inhibitors; NRTI: nucleoside/ nucleotide reverse transcriptase inhibitors; Pl: protease inhibitors.

analogue mutations (TAMs). All resistance mutations are shown in Table 2. The most common HIV-1 subtype was circulating recombinant form 02_AG (CRF02_AG), found in 13/15 (87\%) patients. After one year of ART, no patient had switched to second-line therapy.

\section{Discussion}

The main finding of this study was that a large proportion of HIV-1 and HIV-1/2 dual infections developed virological failure (46\%) after a median follow-up of six months. Furthermore, over half of these patients developed resistance - predominantly to NNRTIs. The CD4 cell count was not an effective indicator of treatment failure.

In the context of ART rollout, the most important drug resistance mutations in HIV-1 were single amino-acid mutations that conferred high-level resistance to NNRTIs. This finding was not surprising, because first-line ART and strategies for preventing mother-to-child transmission were based on NNRTIs. In this study, over half the patients with NNRTI resistance harbored the K103N mutation; thus, detection of this sentinel mutation may be useful in expanded surveillance activities for estimating the prevalence of NNRTI resistance.

Although nine patients developed clinically important mutations to either NRTIs or NNRTIs or both, none had been identified and switched to second-line therapy.
The CD4 cell count was a poor predictor of treatment failure, which underscored the need for implementing virological measures.

This was the first study on HIV-1 resistance in Guinea-Bissau. Knowledge is scarce about resistance mutations in patients with HIV-1/2 dual infections. Thus, despite the small sample size, our results provided valuable information about this relatively unexplored population. Some patients with HIV-1 infections had been coincidentally treated with a first-line PI-based regimen, because they were assumed initially to be infected with HIV-1/2. This provided the opportunity to examine resistance in the context of a PI-based, rather than an NNRTI-based regimen.

Unfortunately, we could not successfully measure resistance in all patients with virological failure, due to the lack of stored plasma or difficulties with the PCR assay for some samples. The latter problem could have been due to poor sample storage in Guinea-Bissau, where electricity is intermittent. Thus, we may have underestimated the proportion of patients with resistance.

No baseline resistance tests had been performed; consequently, we could not determine whether the observed resistance was transferred or acquired. The one patient with an NNRTI-resistant virus that did not receive an NNRTI may represent a case of transmitted resistance; however, it also may represent a previous, 
Table 2 Distribution of resistance-associated mutations among 15 patients with viral loads $>1000$ copies/ml, at 3-12 months after ART initiation

\begin{tabular}{|c|c|c|c|c|c|c|c|c|c|c|c|}
\hline Patient & Sex & $\begin{array}{l}\text { HIV } \\
\text { type }\end{array}$ & $\begin{array}{l}\text { HIV-1 } \\
\text { subtype }\end{array}$ & $\begin{array}{l}\text { Initial } \\
\text { CD4 }\end{array}$ & $\begin{array}{l}\text { Baseline } \\
\text { viral load }\end{array}$ & ART & $\begin{array}{l}\text { Time from ART to } \\
\text { re-sistance test (days) }\end{array}$ & $\begin{array}{l}\text { NNRTI } \\
\text { resistance }\end{array}$ & NRTI resistance & PI resistance & $\begin{array}{l}\text { Predicted resistance to } \\
\text { the following agents }\end{array}$ \\
\hline 1 & M & HIV-1 & CRF02_AG & 32 & 132,355 & $\mathrm{AZT}+3 \mathrm{TC}+\mathrm{EFV}$ & 319 & K103N & $\mathrm{M} 184 \mathrm{M} / \mathrm{V}$ & None & EFV/NVP, 3TC/FTC. \\
\hline 2 & $\mathrm{~F}$ & HIV-1 & CRF02_AG & 33 & 61,978 & $A Z T+3 T C+N V P$ & 362 & K103N Y188CY & None & L10I/N/F/R/Y & $\begin{array}{l}\text { EFV/NVP. Resistance to most PIs } \\
\text { when present with other mutations. }\end{array}$ \\
\hline 3 & $\mathrm{~F}$ & HIV-1/2 & CRF02_AG & 279 & 11,348 & $A Z T+3 T C+I N D / r$ & 177 & None & None & None & None \\
\hline 4 & M & HIV-1/2 & CRF02_AG & 50 & 360,158 & $A Z T+3 T C+I N D / r$ & 161 & K101E & None & K2OR/M/ITTN & $\begin{array}{l}\text { Intermediate NVP. Low-level ETR, } \\
\text { RPV, EFV. Potentially low-level NFV } \\
\text { resistance. }\end{array}$ \\
\hline 5 & M & HIV-1 & CRF02_AG & 207 & 55,650 & $A Z T+3 T C+E F V$ & 114 & None & None & None & None \\
\hline \multirow[t]{4}{*}{6} & M & HIV-1 & CRF02_AG & 46 & 360,978 & $A Z T+3 T C+E F V$ & 203 & K103N K101E/K & M184MV & None & High-level 3TC/FTC. \\
\hline & & & & & & & & & & & Low-level ddl, ABC. \\
\hline & & & & & & & & & & & High-level EFV/NVP. \\
\hline & & & & & & & & & & & Low-level EFV, ETR, RPV. \\
\hline \multirow[t]{3}{*}{7} & $\mathrm{~F}$ & HIV-1 & A & 40 & 216,270 & $A Z T+3 T C+N V P$ & 126 & $\mathrm{~K} 103 \mathrm{~N}$ & M184V & L10I/N/F/R/Y & High-level 3TC/FTC. \\
\hline & & & & & & & & & & & High-level EFV/NVP. \\
\hline & & & & & & & & & & & $\begin{array}{l}\text { Resistance to most Pls when } \\
\text { present with other mutations. }\end{array}$ \\
\hline 8 & $F$ & HIV-1/2 & CRF02_AG & 258 & 46,763 & $A Z T+3 T C+I N D / r$ & 189 & None & None & None & None. \\
\hline 9 & M & HIV-1 & CRFO2_AG & 159 & 869,295 & $A Z T+3 T C+E F V$ & 281 & None & None & None & None. \\
\hline 10 & F & HIV-1 & CRF02_AG & 94 & 485,983 & $A Z T+3 T C+N V P$ & 98 & V106A Y188C & None & $\mathrm{K} 20 \mathrm{R} / \mathrm{M} / \mathrm{I} / \mathrm{T} N$ & $\begin{array}{l}\text { High-level NVP, low-level EFV. } \\
\text { Potentially low-level NFV resistance. }\end{array}$ \\
\hline 11 & $\mathrm{~F}$ & HIV-1 & CRF02_AG & 149 & 212,560 & $A Z T+3 T C+N V P$ & 344 & $\mathrm{~K} 103 \mathrm{~N}$ & None & None & High-level EFV/NVP. \\
\hline \multirow[t]{2}{*}{12} & M & HIV-1 & CRF02_AG & 107 & 34,698 & $A Z T+3 T C+E F V$ & 193 & None & M184MV M184 V/I & $\mathrm{K} 20 \mathrm{R} / \mathrm{M} / \mathrm{I} / \mathrm{TN}$ & High-level 3TC/FTC. \\
\hline & & & & & & & & & & & $\begin{array}{l}\text { Low-level ABC, ddl. Potentially } \\
\text { low-level NFV resistance. }\end{array}$ \\
\hline \multirow[t]{3}{*}{13} & $\mathrm{~F}$ & HIV-1 & A & 71 & $25,000,000$ & $\mathrm{D} 4 \mathrm{~T}+3 \mathrm{TC}+\mathrm{NVP}$ & 98 & Y181C & T69D & L10I/V/R/Y & Low-level ddl. \\
\hline & & & & & & & & & & & High-level NVP. \\
\hline & & & & & & & & & & & $\begin{array}{l}\text { Resistance to most Pls when } \\
\text { present with other mutations. }\end{array}$ \\
\hline 14 & M & HIV-1 & CRF02_AG & 147 & 185 & $A Z T+3 T C+N V P$ & 91 & None & None & L33F & $\begin{array}{l}\text { Contributed resistance to } \\
F P V / r, D R V / r, L P V / r, A T V / r, T P V / r\end{array}$ \\
\hline 15 & M & HIV-1 & CRF02_AG & 252 & Un-detectable & $\mathrm{AZT}+3 \mathrm{TC}+\mathrm{EFV}$ & 185 & None & None & None & None. \\
\hline
\end{tabular}

M: Male, F: Female, AZT: Zidovudine, D4T: Stavudine, 3TC: Lamivudine, NVP: Nevirapine, EFV: Efavirenz, IND/r: Ritonavir-boosted indinavir, ABC: Abacavir, ddl: Didanosine, FPV: Fosamprenavir, DRV: Darunavir, LPV: Lopinavir, ATV: Atazanavir, TPV: Tipranavir, NFV: Nelfinavir, ETR: Etravirine, RPV: Rilpivirine. 
unrecorded exposure to ART. In Senegal, the prevalence of transmitted drug resistance was $4.16 \%$ for NRTIs and $1.04 \%$ for PIs [13]. In Guinea-Conacry, the prevalence of primary resistance was $8.6 \%$ in patients naïve to ART [12]. In our study, at ART initiation, patients had low CD4 cell counts; this only occurs several years after primary infection. This finding argues against transferred resistance, because it is unlikely that this can be detected many years after a primary infection.

Studies in low- and middle-income countries have indicated, that after 12 months of ART, 82-91\% of patients achieve viral suppression [17]. However, a review of 89 studies from Sub-Saharan Africa showed 78\% viral suppression after six months of ART [18]. The present study, showed only $54 \%$ viral suppression; however, our shorter follow-up time made comparisons with other studies difficult.

A previous survey of acquired resistance showed that, among those experiencing therapy failure, $60-70 \%$ had developed drug resistance [17]. We identified drug resistance in $60 \%$ of patients with virological failure; this finding suggested that $40 \%$ developed treatment failure for reasons other than resistance. Thus, when viral load is used as the only indicator for switching to costlier second-line regimens, a large proportion of patients may switch unnecessarily.

The majority of patients was infected with the CRF02_AG subtype, and a minority harbored subtype A, consistent with previous studies in this region [19]. Genetic differences between subtypes might influence drug resistance pathways; therefore it may be difficult to generalize our results to studies performed in different geographic regions $[20,21]$.

In conclusion, we found a high virological failure rate and rapid development of NNRTI resistance among patients with HIV-1 and HIV-1/2 dual infections in Guinea-Bissau. It remains to be determined whether a more robust PI-based treatment regimen might benefit this population more than NNRTIs. Further studies are warranted on drug resistance in patients with HIV-1/2 dual infections.

\section{Abbreviations}

ART: Antiretroviral treatment; CRF02_AG: Circulating recombinant form 02_AG; IQR: Interquartile range; NNRTI: Non-nucleoside reverse transcriptase inhibitor; NRTI: Nucleoside/nucleotide reverse transcriptase inhibitors; PI: Protease inhibitor; TAMs: Thymidine analogue mutations.

\section{Competing interests}

The authors declare that they have no competing interests.

\section{Authors' contributions}

SJ, MT, BLH, LØ, CW, and AL analyzed and interpreted data; CM and DdaS carried out the clinical assessment; SEE carried out analyses of viral load; SJ drafted the manuscript; SJ, MT, BLH, LØ, CW and AL critically revised the manuscript for intellectual content. All authors read and approved the final manuscript.

\section{Acknowledgements}

Financial support from Aarhus University is gratefully acknowledged. The Global Fund to Fight AIDS, TB and Malaria supported the data collection during 2009-2010, provided through the 'Secretariado Nacional de Luta contra o Sida' in Guinea-Bissau. The authors are grateful to the health care staff at the HIV clinic at HNSM for providing medical care to the patients with HIV infections and for allowing us access to data for this study. We extend special thanks to the West African Platform for HIV Intervention Research (WAPHIR) and the International Epidemiologic Databases to Evaluate AIDS (leDEA) for their collaboration and for financial support for The Bissau HIV cohort. We acknowledge The National Cancer Institute (NCI), the Eunice Kennedy Shriver National Institute of Child Health \& Human Development (NICHD) and the National Institute of Allergy and Infectious Diseases (NIAID) of the U.S. National Institutes of Health (NIH), for supporting the International Epidemiologic Databases to Evaluate AIDS (leDEA) under Award Number U01Al069919.

The Bissau HIV cohort study group comprises: Amabelia Rodrigues, David da Silva, Zacarias da Silva, Candida Medina, Ines Oliviera-Souto, Lars Østergaard, Alex Laursen, Morten Sodemann, Peter Aaby, Anders Fomsgaard, Christian Erikstrup, Jesper Eugen-Olsen and Christian Wejse (chair).

\section{Author details}

${ }^{1}$ Bandim Health Project, Indepth Network, Apartado 861, Bissau, Guinea-Bissau. ${ }^{2}$ Department of Infectious Diseases, Aarhus University Hospital, Palle Juul-Jensens Boulevard 99, 8200 Aarhus N, Denmark. ${ }^{3}$ Department of Clinical Immunology, Aarhus University Hospital, Palle Juul-Jensens Boulevard 99, 8200 Aarhus N, Denmark. ${ }^{4}$ National HIV Programme, Ministry of Health, Bissau, CP 1013 Bissau, Guinea-Bissau. ${ }^{5}$ Department of Clinical Microbiology, Aarhus University Hospital, Palle Juul-Jensens Boulevard 99, 8200 Aarhus N, Denmark. ${ }^{6} \mathrm{GloHAU}$, Center for Global Health, School of Public Health, Aarhus University, Bartholins Allé 2, 8000 Aarhus C, Denmark.

Received: 25 December 2014 Accepted: 26 February 2015

Published online: 11 March 2015

\section{References}

1. Gupta RK, Jordan MR, Sultan BJ, Hill A, Davis DH, Gregson J, et al. Global trends in antiretroviral resistance in treatment-naive individuals with HIV after rollout of antiretroviral treatment in resource-limited settings: a global collaborative study and meta-regression analysis. Lancet. 2012;380:1250-8.

2. Sigaloff KC, Hamers RL, Wallis CL, Kityo C, Siwale M, Ive P, et al. Unnecessary antiretroviral treatment switches and accumulation of HIV resistance mutations; two arguments for viral load monitoring in Africa. J Acquir Immune Defic Syndr. 2011;58:23-31.

3. Pasquet A, Messou E, Gabillard D, Minga A, Depoulosky A, Deuffic-Burban S, et al. Impact of drug stock-outs on death and retention to care among HIV-infected patients on combination antiretroviral therapy in Abidjan. Cote d'Ivoire PLoS One. 2010;5:e13414.

4. Boulle A, Van Cutsem G, Cohen K, Hilderbrand K, Mathee S, Abrahams M, et al. Outcomes of nevirapine- and efavirenz-based antiretroviral therapy when coadministered with rifampicin-based antitubercular therapy. JAMA. 2008;300:530-9.

5. WHO. CONSOLIDATED GUIDELINES on the use of ANTIRETROVIRAL DRUGS FOR TREATING AND PREVENTING HIV INFECTION. 2013. http://apps.who.int/ iris/bitstream/10665/85321/1/9789241505727_eng.pdf?ua=1. Accessed 24 Febr 2015

6. Klein K, Lang T, Saussele T, Barbosa-Sicard E, Schunck WH, Eichelbaum M, et al. Genetic variability of CYP2B6 in populations of African and Asian origin: allele frequencies, novel functional variants, and possible implications for anti-HIV therapy with efavirenz. Pharmacogenet Genomics. 2005;15:861-73.

7. Da Silva ZJ, Oliveira I, Andersen A, Dias F, Rodrigues A, Holmgren B, et al. Changes in prevalence and incidence of HIV-1, HIV-2 and dual infections in urban areas of Bissau, Guinea-Bissau: is HIV-2 disappearing? AIDS. 2008:22:1195-202.

8. Wilkins A, Ricard D, Todd J, Whittle H, Dias F, Paulo Da Silva A. The epidemiology of HIV infection in a rural area of Guinea-Bissau. AIDS. 1993;7:1119-22.

9. Poulsen AG, Aaby P, Gottschau A, Kvinesdal BB, Dias F, Molbak K, et al. HIV-2 infection in Bissau, West Africa, 1987-1989: incidence, prevalences, and routes of transmission. J Acquir Immune Defic Syndr. 1993;6:941-8.

10. Witvrouw M, Pannecouque C, Switzer WM, Folks TM, De Clercq E, Heneine W. Susceptibility of HIV-2, SIV and SHIV to various anti-HIV-1 compounds: 
implications for treatment and postexposure prophylaxis. Antivir Ther. 2004;9:57-65.

11. Thiam M, Diop-Ndiaye H, Diouf AD, Vidal N, Ndiaye O, Ndiaye I, et al. HIV-1 genetic diversity and drug resistance among Senegalese patients in the public health system. J Clin Microbiol. 2013;51:578-84.

12. Charpentier C, Bellecave P, Cisse M, Mamadou S, Diakite M, Peytavin G, et al. High prevalence of antiretroviral drug resistance among HIV-1-untreated patients in Guinea-Conakry and in Niger. Antivir Ther. 2011;16:429-33.

13. Diop-Ndiaye H, Toure-Kane C, Leye N, Ngom-Gueye NF, Montavon C, Peeters $\mathrm{M}$, et al. Antiretroviral drug resistance mutations in antiretroviral-naive patients from Senegal. AIDS Res Hum Retroviruses. 2010;26:1133-8.

14. Jespersen S, Honge BL, Oliveira I, Medina C, Da Silva Te D, Correira FG, et al. Cohort profile: the Bissau HIV Cohort-a cohort of HIV-1, HIV-2 and co-infected patients. Int J Epidemiol. 2014;22:201.

15. Honge BL, Bjarnason Obinah MP, Jespersen S, Medina C, Te Dda S, Da Silva ZJ, et al. Performance of 3 rapid tests for discrimination between HIV-1 and HIV-2 in Guinea-Bissau, West Africa. J Acquir Immune Defic Syndr. 2014;65:87-90

16. Shafer R. Stanford HIV RT and protease sequence database. 2014. http://hivdb.stanford.edu; Accessed 24 Febr 2015

17. WHO. HIV Drug Resistance Report 2012. http://apps.who.int/iris/bitstream/ 10665/75183/1/9789241503938_eng.pdf; Accessed 24 Febr 2015.

18. Barth RE, van der Loeff MF, Schuurman R, Hoepelman Al, Wensing AM Virological follow-up of adult patients in antiretroviral treatment programmes in sub-Saharan Africa: a systematic review. Lancet Infect Dis. 2010;10:155-66.

19. Esbjornsson J, Mild M, Mansson F, Norrgren H, Medstrand P. HIV-1 molecular epidemiology in Guinea-Bissau, West Africa: origin, demography and migrations. PLoS One. 2011:6:e17025.

20. Brenner BG, Oliveira M, Doualla-Bell F, Moisi DD, Ntemgwa M, Frankel F, et al. HIV-1 subtype C viruses rapidly develop K65R resistance to tenofovir in cell culture. AIDS. 2006;20:F9-13.

21. Holguin A, Paxinos E, Hertogs $\mathrm{K}$, Womac C, Soriano V. Impact of frequent natural polymorphisms at the protease gene on the in vitro susceptibility to protease inhibitors in HIV-1 non-B subtypes. J Clin Virol. 2004;31:215-20.

\section{Submit your next manuscript to BioMed Central and take full advantage of:}

- Convenient online submission

- Thorough peer review

- No space constraints or color figure charges

- Immediate publication on acceptance

- Inclusion in PubMed, CAS, Scopus and Google Scholar

- Research which is freely available for redistribution 